accompanied by vomiting. Thirteen months ago he had an attack more than usually severe, which was followed almost immediately by a dimness of vision of left eye. The sight of this eye remained dim for three months; he then had " horrible pain in the head," followed by dimness of right eye. Three weelss later he had two fits, which left him unconscious for a short time, and rendered him totally blind, but did not affect either hands or legs. He remained in this condition for some time (exact time not known). He then, by looking sideways, was able to discern very faintly the outline of a bright jet of gas. At the present time he can direct his hand towards any bright flame with precision. Both discs are quite white; vessels slightly tortnous.

Feb. 1868. - Now states that he has smoked half an ounce of tobacco every day for several years past. Vision: "I can tell if it be a big or a little man that is passing me in the street now." Discs unaltered in appearance.

CASE 2.-C. F-—, a married woman, aged fifty, came under the care of Mr. Pridgin Teale in Nov. 1866, and was transferred to my care. She came on account of a sudden impairment of vision. Married at twenty-five; never pregnant. Three or four years after marriage took syphilis from her husband. Several years ago nursed her mother during a long illness, and ever since she has suffered from shooting pains in the back and legs. She describes the pains as "jumping," and says that they prevent her sleeping at night. Sensation of numb. ness in the feet, as if "walking on cockle-shells." Her gait is unsteady, and she has difficulty in balancing herself when her feet are placed close together; muscular power unimpaired. Ten days ago she awoke with dimness of sight and double vision. There is ptosis of the left eyelid, and paralysis of the internal rectus of the same eye. On examination by the ophthalmoscope, both dises are found to be white, and present the appearance of simple atrophy. Vision barely No. 20 Jaeger.

Jan. 1867.-No improvement; dises very white. Left eye cannot read No. 20 Jaeger; right eye reads No. 16.

March 5th. - Ordered iodide of potassium. Under this treatment she rapidily improved.

16th.-Left eye reads No. 20 Jaeger; right eye No. 4. Discs resuming a natural appearance.

April 9th.--Reads No. 4 with each eye. Optic discs almost natural. The general health is also much improved; she walks with more steadiness; double vision has disappeared, but ptosis and strabismus remain.

CASE 3.-March 26th, 1867.-Thomas $\mathrm{R}$ years, complains of defective vision. His mother, who accompanies him, gives the following history :-The whole of her children have shown a decided phthisical tendency. One or two have died during early childhood of consumption, and the remainder still living are all delicate. The subject of the present history is a pale, weak-looking boy, and decidedly small for his age. When two years old he suffered from "fits," which left him very weak. For the past six weeks he has complained of acute pain in the right side of the head. After this pain had existed three weeks, his sight became somewhat dim. Alarming symptoms of increasing blindness rapidly followed, and warned his parents to seek medical aid. His vision previously had been good. He has of late suffered from a heavy, numb sensation in the left arm and leg, there being a slight, though not a decided, loss of motor power in the arm.

History of right disc.-It is in the acute stage of optic neuritis; it is larger in circumference than its fellow, and, perhaps, somewhat more raised and vascular. The vessels are slightly tortuons ; vision sees shadows only.

April 9th. - The disc remains unaltered in appearance; vision-shadows only.

24th.-The disc is less vascular and smaller, and the vessels more tortuous. The pupil is dilated, and acts sluggishly.

30th. - Atrophy of disc commencing.

May 7th.-Atrophy of disc very evident; vision-shadows only.

July 4th.-Disc small; vessels more tortuous; vision entirely gone.

Oct. 22nd.-No alteration in appearance of disc. Vision gone.

History of left disc.-March 26th : Is in the early stage of optic neuritis. It is less raised and vascular than the right. Vessels slightly tortuous. Vision, No. 4 Jaeger.

April 9th. - The disc is more raised, and vascularity more apparent. Vision, 16 Jaeger.

24th. - Disc less vascular; pupil dilated. Vision, not 20 Jaeger.

30th.-Vision somerhat improved. Dise commencing to atrophy.
May 7th.-Atrophy of disc very apparent. Vision improving.

July 4th.-Marked improvement in vision. Although the disc is still very white and the vessels tortuous, he can read No. 1 Jaeger.

12th. -Dise assuming a faint capillary tint.

August.-Disc almost normal in appearance.

October. - Dise quite normal in appearance. Vision, 1 Jaeger.

In this case cod-liver oil was prescribed, and the patient improved very materially in his general health under its influence. On first seeing the boy, 1 made a careful drawing of both discs, and used it as a means of comparison at each ophthalmoscopic examination.

CASE 4.-April, 1867. Sarah $\mathrm{H}-$, aged thirty-nine years, has been under observation for the past two years. She gives the following brief history. She has been delicate since puberty, having frequently suffered from bronchitis and dyspepsia. Her grandmother lost the use of one side shortly before her death, but no other member of her family suffered from paralysis. Four years ago she had two slight attacks of hemiplegia, which affected the left hand and leg. Sight was totally lost immediately after the fits, and returned only at the expiration of four months, when she could see the fire blaze. Since that time vision bas gradually improved.

Present condition.-Vision of right eye : reads 4 Jaeger. Vision of left eye : counts fingers.

Optic discs. - Both discs are pearly white. Vessels small, but not tortuous.

CASE 5.-A pril, 1867. Wm. C-_, aged thirty years, snffers from atrophied discs. He makes the following statement :"Nine years ago I suffered from rheumatic fever, and was very delirious during part of the time I lay in bed. Two years after the fever I became both deaf and blind, but sight had been gradually failing ever since the fever. I have been under Mr. Pridgin Teale's care for a long time. Four years ago I can positively say I was quite blind."

Present condition.-Vision : with each eye reads 16 Jaeger. Both discs brilliantly white.

Oct. 22nd. - Since last seeing the patient he has been spending some time at Harrogate and Ilkley. The improvement in his vision has been very marked, and he attributes it to his improving health. Vision : reads with difficulty No. 4 Jaeger. Discs unaltered in appearance.

Park-square, Leeds, July, 1868 .

\section{DISLOCATION OF THE METACARPUS.}

By THOMAS F. RAVEN, L.R.C.P., HOUSB-SURGEON TO THE KINT AND CANTERBURY HOSPITAL,

Drslocation of the metacarpus, owing to the great strength of the ligaments binding it to the carpus, and the very limited movement permitted in the carpo-metacarpal and inter-metacarpal joints, is of rare occurrence, even when produced by severe laceration and crushing of the hand. The dislocation is said to be invariably compound. Simple dislocation of the metacarpal bone of the thumb is occasionally met with, but such a laxation cannot be considered analogous to that of the other bones of the series, because, granting that it is a metacarpal bone, the first, in its articulation with the carpus, its functions and mobility, differs widely from the remaining four, which are not only less movable at their junction with the carpus, but are also firmly bound to each other. I have recently met with a case of simple dislocation backwards of the second, third, and fourth metacarpal bones of the left hand, which I think deserves to be recorded.

Thomas L_- aged seventy-seven, was kicked by a horse on the back of the left hand, and was brought to the Kent and Canterbury Hospital, on March 21st, soon after the accident had happened. Upon examining the hand, I found a prominent ridge, consisting of the carpal extremities of the second, third, and fourth metacarpal bones, projecting on the back of the hand, over which the integument was but slightly stretched. The metacarpo-phalangeal joints on the dorsal aspect of the hand presented a concavity instead of a convexity, owing to the tilting up of the carpal ends of the displaced bones. Upon placing the hands in the attitude of supplication-i.e., with the tips of the thumbs and little fingers coinciding, - there was 
found to be shortening to the extent of a quarter of an inch of the left index, middle, and ring fingers. As there was no swelling of the hand, the outline of each dislocated bone was traced along the shaft; and the expanding carpal extremity could be clearly defined. The ligaments connecting the bones laterally could be felt, and appeared to be untorn. There was no visible deformity in the palm, and the plane of the fingers was not altered.

As very little pain was felt, and there was not much tension of the skin, the dislocation was left unreduced for an hour for the purpose of obtaining corroborative testimony as to the mature of the case. The only doubt entertained was whether the heads of the bones had not been broken off, and the shafts subsequently displaced, as in a Collis' fracture. But upon eareful re-examination of the hand it appeared that this could not be the nature of the injury, as the carpal ends of the bones, with the even edges of their articulating processes, could be traced beneath the skin. The dislocated bones were also measured, and found to correspond in length to those of the right hand : there was no mobility to be obtained between them, or crepitus upon attempting to move them.

The dislocation was not reduced without seme little trouble, owing partially to the difficulty of grasping and making extension from the carpus. The reduction was accomplished by a rotatory movement of the metacarpus after extension had been employed. The three bones slipped back as one, but without an audible snap, and no crepitus was felt.

With regard to the cause of the luxation, as there were no external marks of violence, except slight grazing of the knuckles, I supposed that having been knocked down by a kick in the chest, which he also sustained, the patient might have fallen upon the hand. He is, however, positive as to the fact of his having been kicked on the back of the hand. $\mathrm{He}$ admits he fell, but states that it was upon the right side, and that the left hand did not come into contact with the ground.

One or two points in connexion with the case are worthy of notice. It is remarkable that the three least movable and most firmly articulated bones of the metacarpus should have been thus displaced; and that in so old a subject the brittle bones should have better resisted force than the tough and rigid ligaments. Sir Astley Cooper states, in his work on Dislocations, that he had never seen a case of dislocation of whe metacarpus, except in connexion with gun-shot wounds and other severe injuries of the hand. In $R$. W. Smith's treatise on Dislocations, that of the metacarpus is not mentioned. Mr. Erichsen says that no metacarpal bone, with exception of the first, admits of dislocation. On referring to the catalogue of the museum at the College of Surgeons, I find that there is there a specimen of partial dislocation of the fourth metacarpal bone backwards. It seems to have lost its conanewion with the os unciforme only, being still articulated to the os magnum. I have consulted many other authorities with the view of obtaining further information about this particular dislocation; but as I bave been unable to find a aingle record of such a case as the one which $I$ have described, it is, as far as $I$ know, unique.

July, 1868.

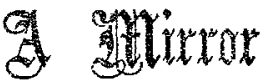

\section{OF THE PRACTICE OF}

\section{MEDICINE AND SURGERY IN THE}

\section{HOSPITALS OF LONDON.}

Nulla autem est alia pro certo noscendi via, nisi quamplurimas et morborum et dissectioum historias, tum aliorum, tum proprias collectas habere, et inter 32 comparare.-HongagN De Sed. et Caus. Morb., lib. iv. Promium.

\section{UNIVERSITY COLLEGE HOSPITAL.}

\section{WOUND OF THE POPLITEAL ARTERY FROM SIMPLE} FRACTURE OF THE FEMUR; AMPUTATION; DEATH.

(Under the care of Mr. CaristopHeR HeatH.)

There wuuld seem to be a general concurrence of surgical opinion as to the best mode of treatment in such a case as the following-a result due, in great part probably, to Mr. Poland's important paper which was published in the “ Gny's Hospital Reports" three years ago.

For the notes of the case we have to thank Mr. Cluff, the house-surgeon.

The patient, a man aged forty-six, was admitted into the hospital on the 4th of August, 1868, with the following his. tory:- Three weeks before the date of his admission, according to his own statement, he was putting on his right boot, and while pulling forcibly at it in order to get it on his foot he felt something give way above the knee. (His right leg had been paralysed a jear before-from what cause could not well be ascertained; but he gradually recovered under medical treat. ment, and, at the time of the acident, had nearly regained the use of the limb.) He was seen almost immediately by a surgeon, who detected a fracture of the femur in its lowest third, and put up the limb at once on the long splint. He suffered a grood deal of pain at the time; but still managed to bear the splint for three weeks, during which time it was left undis. turbed. On the 3rd of August the pain, which bad been growing gradually worse, became wholly intolerable, and the long splint was removed. Next day he was sent to the hospital.

On admission he presented a very blanched appearance; lips, tongue, and eyelids extremely pallid; pulse rapid and feeble. The right $\mathrm{l} g \mathrm{~g}$ was enormously swollen throughout, and he complained ot intense pain in it-most severe about the knee, but radiating thence up and down the limb. The right knee was unduly prominent, and above it a distinct de. pression was to be felt. The skin in front and on the inner side of the knee was somewhat reddened. On manipulating the limb, great subcutaneous cedema was found everywhere. On the inner side of the knte deep fluctuation could be doubt. fully felt; but he did not complain of esteecial pain on pressure being made in this or any other situation. The right limb felt hotter throughout than the left; and pulsation was distinct in both tibials on the right side. He could move the toes of the injured limb perfectly well. He stated that he had aweated profusely during the previous week, but he had not had any rigors.

The patient was seen by $\mathrm{Mr}$. Heath on the evening of his admission. With the view of ascertaining the character of the find which gave the deep fluctuation on the inner side of the knee, Mr. Heath made an exploratory puncture. Nothing came from the puncture but a little blood. The puncture was closed with plaster, a large poultice was applied over the knee, and the ammonia-and-bark mixture and alcoholic stimulants were freely administered.

He passed a restless night, and was seen on the following day by Mr. Erichsen and Mr. Heath in consultation. It was agreed that fluid of some kind lay deeply in the vicinity of the fracture, and with a view to further examination the patient was brought into the operating theatre, and put under chloro. form. Mr. Heath then made an incision to the outside of the puncture of the previous evening, so as to admit the forefinger, which, when introduced, readily felt the fractured ends of the bone, and detected around them a large cavity filled mainly with clotted blood. Immediate amputation was resolved on, and the operation was performed by Mr. Heath below the middle of the thigh by a long anteriar and a short posterior flap, the sharp end of the fractured bone being removed with the saw.

On examining the amputated limb, a large mass of clotted blood was found lying close to the bone and surrounding the fractured ends. It reached from the middle of the thigh to the bottom of the popliteal space; and at the lower part was a mass of fibrin arranged in lamellæ, which presented at the first view the appearance of an aneurismal sac. No communication was apparent, at first sight, between the niass of effused blood and the popliteal vessels, to which the fibrinous lamellw just mentioned were closely adherent; but the azygos artery was found torn from the popliteal trunk, the torn end lying in the middle of the effused blood. The little vessel was quite impervious; on cutting it out, it was found impossible to pass a probe through it. On cautiously separating the laminated fibrin from the popliteal vessels, a hole in the artery, passing obliquely through its coats, and large enough to admit a No. 3 catheter, was disclosed. This hole was about opposite the point at which the azygos artery ought to have arisen. The vein was uninjured. The fracture of the bone ran very obliquely from about five inches abore the knee to the inner condyle; and the ends of the fragments (especially the lower end of the upper one, which lay in close proximity to the wound in the popliteal vessel) were sharply pointed. There was no evident disease of the bone ; it was of normal hardness, and of normal appearance in every way. 